\title{
Gear shift simulation by using virtual prototype
}

\author{
Ales Prokop ${ }^{1}$, Kamil Rehak ${ }^{2}$ \\ Brno University of Technology, Technicka 2896/2, 61669, Brno, Czech Republic \\ ${ }^{2}$ Corresponding author \\ E-mail: ${ }^{1}$ prokop.a@fme.vutbr.cz, ${ }^{2}$ rehak@fme.vutbr.cz \\ Received 1 November 2019; accepted 7 November 2019 \\ DOI https://doi.org/10.21595/vp.2019.21160 \\ Check for updates \\ Copyright (C) 2019 Ales Prokop, et al. This is an open access article distributed under the Creative Commons Attribution License, which \\ permits unrestricted use, distribution, and reproduction in any medium, provided the original work is properly cited.
}

\begin{abstract}
The presented paper is focused on the simulation of gear shift and prediction of whole gearbox dynamic behavior during gear shift. For this complex task the methodology for simplified gearbox was developed first. The whole methodology is divided into three different level of numerical model, where each of them was developed and validated by technical experiment. Afterwards the methodology was applied on more complex gearboxes, in presented case the heavy-duty gearbox concept. The virtual prototype was extended by gear shift option. The numerical sensitivity study of different gear shift time, which are simulated by different clutch activation and deactivation, was performed and the surface normal velocity and torque were evaluated and compared. The simulation was performed to find the optimal gear shift progress with minimal affects vehicle comfort. For this purpose, the surface normal velocity is evaluated, which is directly connected to emitted noise of whole gearbox.
\end{abstract}

Keywords: vibration, gear shift, surface normal velocity.

\section{Introduction}

The development phase of gearbox is very time and money consuming because of increase requirements on efficiency, transmitted torque and lower built-in dimensions. To be success with final product the several optimization loops are very often performed. To decrease number of prototypes, where the technical properties are measured directly on the $3 \mathrm{D}$ object, the numerical simulation are used.

The numerical simulations can be performed on different level of complexity. To evaluate the numerical approach at each level, the technical experiment is performed. The parameters, which are connected to passengers or operator comfort, are evaluated - vibration, noise.

The simplest level of model is focused on determination of modal properties. Gearboxes are affected by many kinds of excitation such as input/output shaft speed, gear mesh frequencies, bearing frequencies. [1] To solve the modal properties, the software ANSYS can be used. The goal is separate the natural frequencies and excitation frequencies, which very often leads to gearbox damage, but this is not possible in all application. For that reason, the numerical model on higher level have to be used to find if the operation conditions are critical or not. The main excitation at gearbox is caused by functional principle of gears contact. The mesh stiffness can be at the basic level modeled by harmonic signal; thus, the excitation force can be applied on the bearing location and the response on structure can be evaluated. That can be used to compare design during optimization.

The highest level of numerical simulation includes real progress of gear mesh stiffness, modal properties of key components, stiffness of key components. There are possible to include other parameters such as variability of input shaft speed based on functional principle of engine, or motor [2].

\section{Methods}

This paper deals with application of virtual prototype to the heavy-duty gearbox, which has been developed on the single stage gearbox. The basic methodology, which consist from three 
different level of complexity was also evaluated by corresponded technical experiment. The methodology enables to include oil behavior, the influence of contact behavior, unbalance, backlash, torque value and transmission error, which is used in several approaches [3, 4]. The software Ansys was used for modal and harmonic analysis. By the modal analysis the geometry and material deviations were verified to real prototype [5]. By the technical experiment the damping coefficient was determined for each natural frequency, which is necessary for next levels of model. The value of harmonic excitation applied to the bearing location were determined based on previous performed technical experiment. The results from numerical simulation were compared to technical experiment. The highest level of model combines multibody simulation (MBS) software ADAMS and finite element method (FEM) by using software Ansys. In ADAMS the parametrical open code was used to enable perform sensitivity study very quickly and with a wide range of customization options for different gearbox applications. The input data are obtained by using FEM.

The MBS model includes flexible bodies, bearing stiffness, gear mesh stiffness, backlash, variable input speed and torque. After creation and validation of methodology the sensitivity studies were performed, which were focused on input variable, tooth damage, backlash $[3,6,7]$.

\section{Virtual prototype}

The whole approach was applied to heavy-duty gearbox concept, where each step was also verified by technical experiment, see Fig. 1 and Fig. 2. The benefits of open code were primarily due to easy modification of structures and in case of heavy-duty gearbox considerable number of gears including gear mesh stiffness or bearings, see Fig. 3.

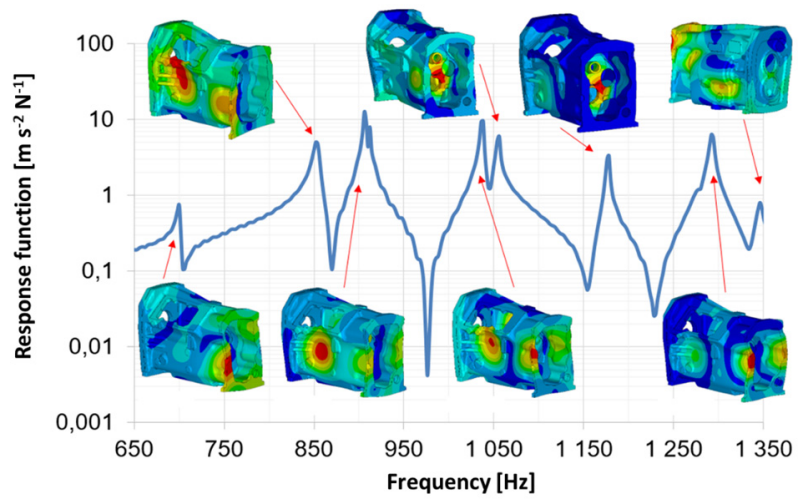

Fig. 1. Modal analysis of gearbox housing

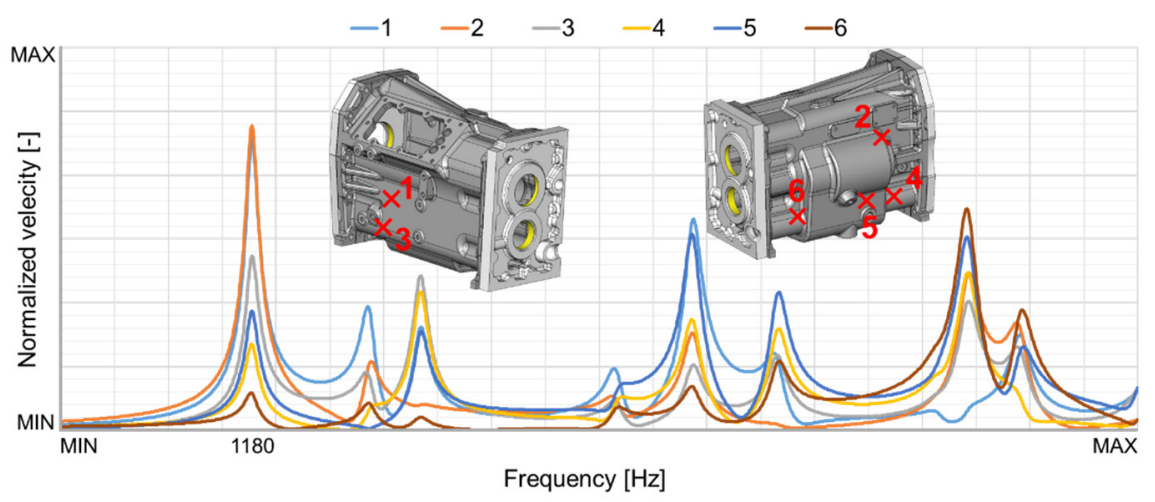

Fig. 2. Harmonic analysis of gearbox housing 
To determine all inputs the software Ansys was used, the gear mesh stiffness was calculated for each gear pairs including their modifications, in similar way as [8]. Modal properties of shafts and housing were transformed by using Craig Bampton modal reduction to flexible bodies. The virtual prototype of heavy-duty gearbox concept enables to set backlash for each gear pairs, variable input speed based on the functional principle of the combustion engine and torque applied on the output side.

When the whole methodology was applied on the heavy-duty gearbox and the virtual prototype was created several sensitivity studies were also performed. [9, 10] Afterwards the extension, which enables gear shift, was written also in open code. The first sensitivity study was performed to see, if the virtual prototype can consider effect of clutch activation and deactivation.

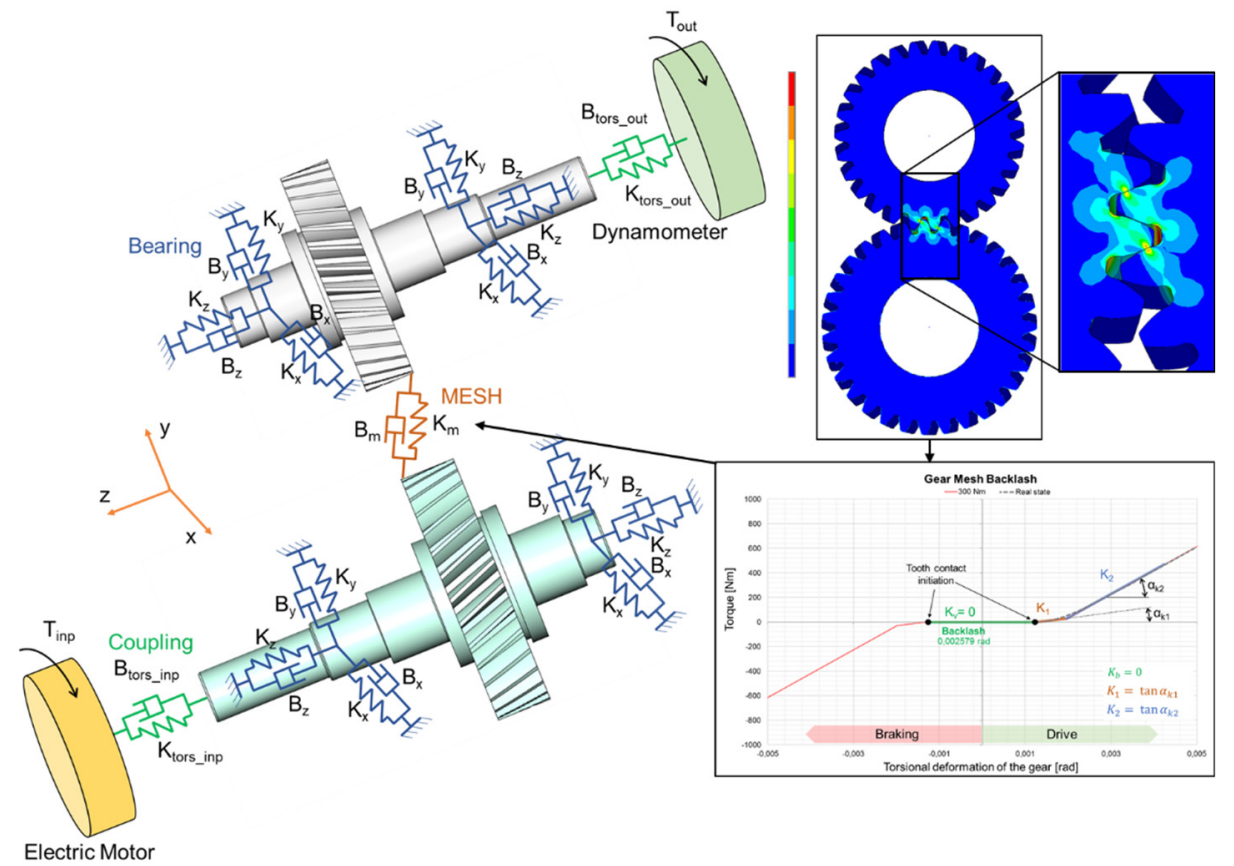

Fig. 3. The basic concept of stiffness and damping of transmission virtual prototype

\section{Results}

The virtual prototype was extended by the shifting functionality to simulate the effect of shifting time, different dependency of hydraulic pressure, different cross of couplings without necessity to use the real prototypes. In this study the influencing of gearbox dynamic behavior by clutch activation and deactivation during shifting up and down is investigated. The clutch deactivation is changing in 0.2-0.4 s. Shifting profiles are shown in Fig. 4.

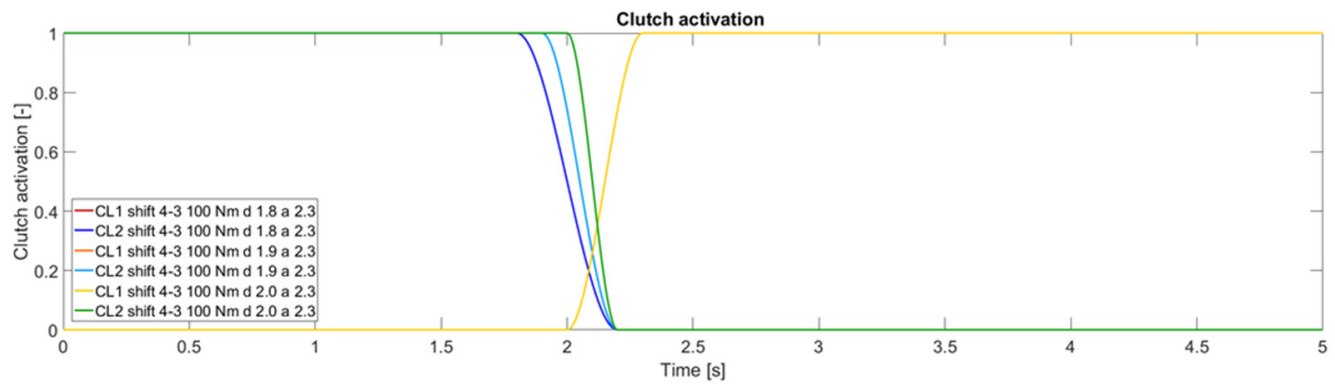

Fig. 4. The progress of clutch activation and deactivation 
The combination of inertia masses and gear shifting causes changes in transmitted torque. The torque difference between shifting up and down is visible on Fig. 5. The carried torque amplitude is higher with decreasing time of the clutch deactivation for both cases. The maximal value of transmitted torque on clutch 1 is higher in case of shifting down. There is also markable the difference in next progress of torque between shifting up and down. To focus on differences of whole structure behavior the surface normal velocity can be evaluated, see Fig. 6. and Fig. 7.
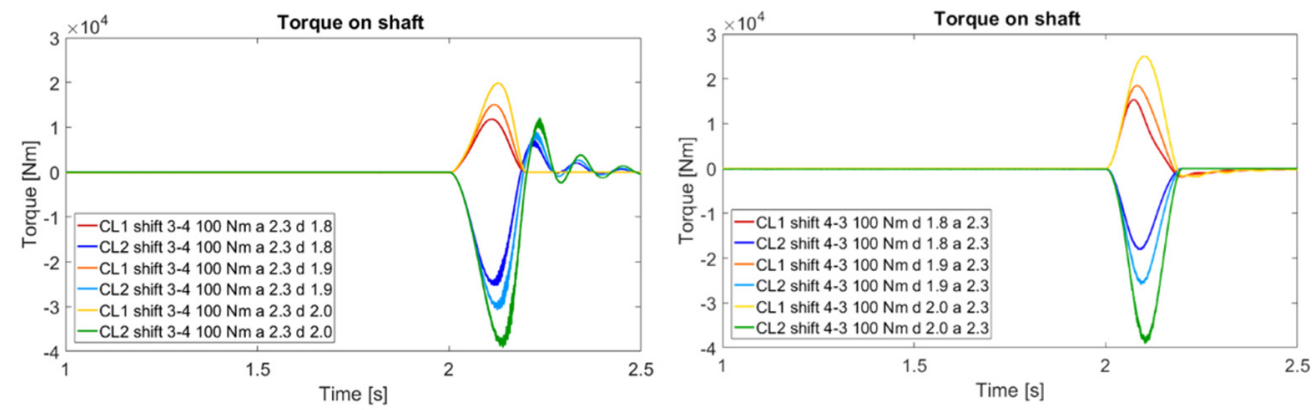

Fig. 5. Torque input and output during gear shift
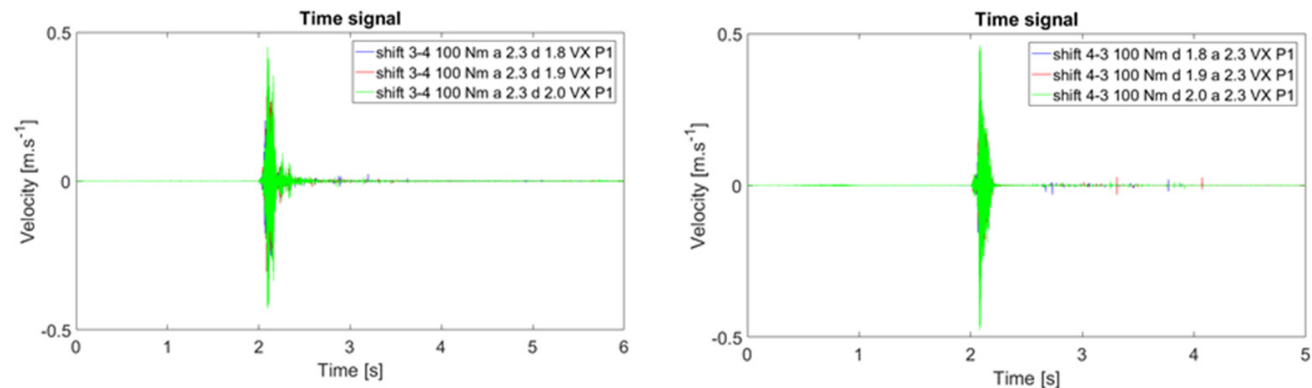

a)
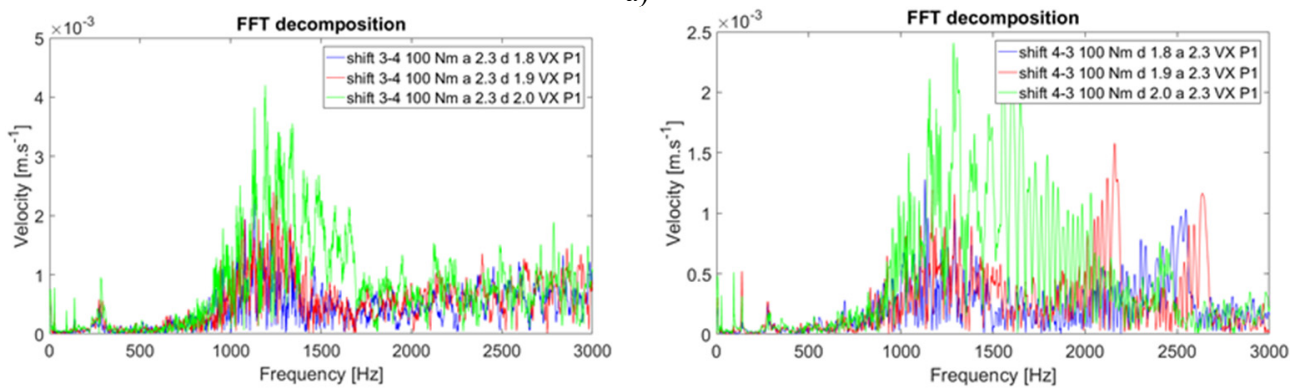

b)

Fig. 6. Surface normal velocity in time and frequency domain for shifting up a) and down b)

Based on the time signal, it is obvious, that the most interesting part from the shifting point of view is at $2 \mathrm{~s}$, when the clutch crosses each other. Based on the results from frequency domain, the shifting down reach slightly higher value of surface normal velocity in wide range of frequency. In case of multispectrum diagram the part before and after shifting, can be compared in cross, when the corresponded gear at stable state is used. The surface normal velocity is slightly higher in case of shifting down at 3 gear. On the other hand, the response on the excitation caused by shifting down is shorter but wide frequency range amplitude increase occurred. With increasing ratio of clutch cross section, the structure response reached higher value of surface normal velocity in critical location. 

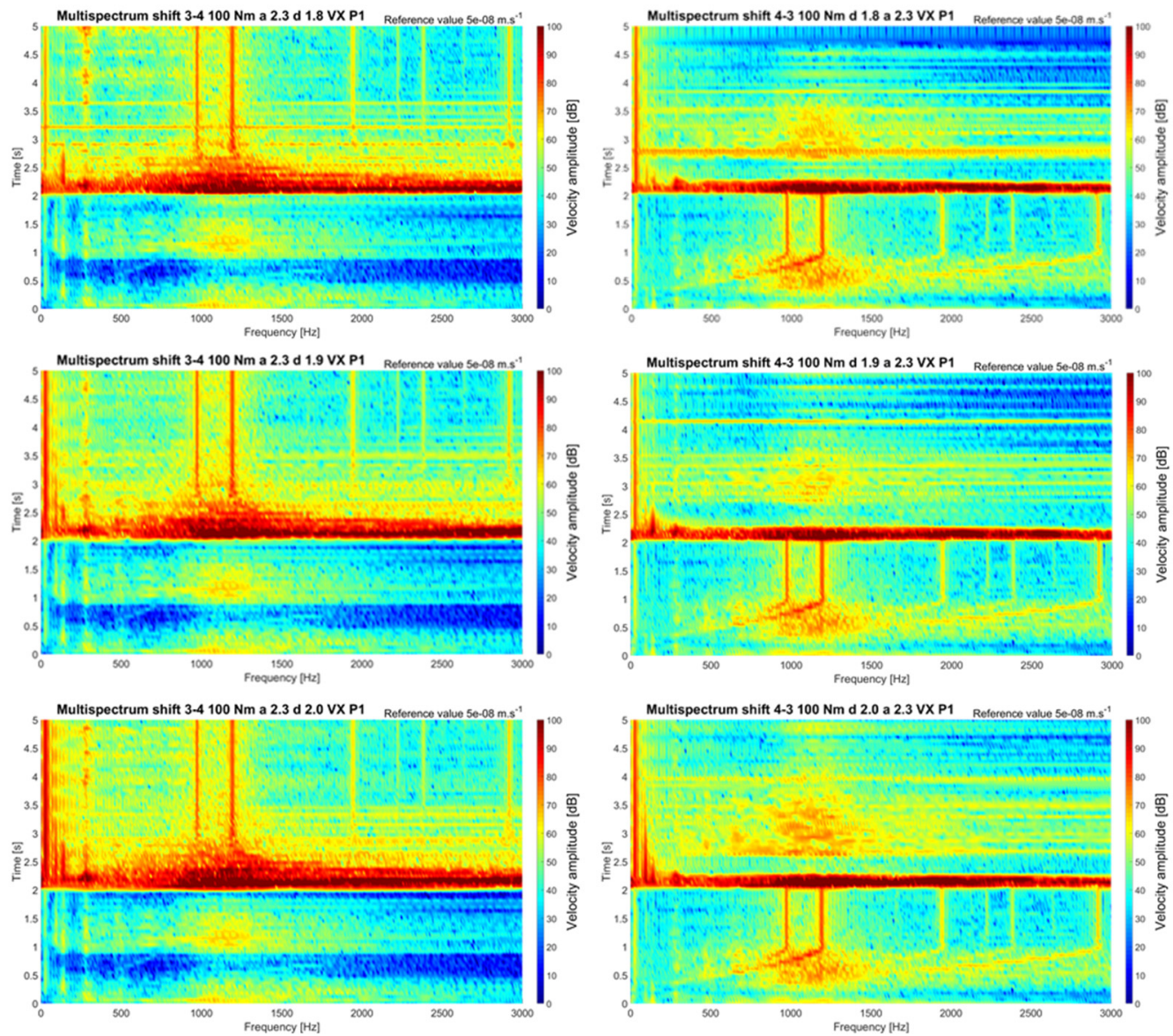

Fig. 7. The basic concept of stiffness and damping of transmission virtual prototype

\section{Conclusions}

The numerical simulation was used for comparison of several gear shifting profiles at shifting up and down. First the whole process of dynamical behavior modelling was validated by technical experiment on single stage gearbox at different complexity level of model. The most complex virtual prototype was built as open code concept to enable fast modification and extension to more complex gearbox concept with several gear pairs. The FEM was used to determine input parameters, which were solved based on the real geometry and operation condition of given heavy-duty gearbox concept. First the virtual prototype was used for simulation at steady state and run up at given gear. The surface normal velocity was evaluated as one of the main output parameters, which is well connected to the emitted noise. Similar approach was used for investigation of gear up and down shifting. The clutch activation and deactivation were changed, where the torque on shaft and surface normal velocity was evaluated. The virtual prototype is suitable tools for prediction of dynamic behavior during gear shifting. Based on presented results both cases have to be investigated to deeply understand the effect of activation and deactivation profile of clutch.

\section{Acknowledgement}

The research leading to these results has received funding from the project FSI-S-17-4104 granted by specific university research of Brno University of Technology. The authors gratefully 
acknowledge this support.

\section{References}

[1] Weis P., Kučera L., Pecháč P., Močilan M. Modal analysis of gearbox housing with applied load. Procedia Engineering, Vol. 192, 2017, p. 953-958.

[2] Drápal L., Vopařil J. Torsional vibration of unconventional crankshaft in four-cylinder passenger car engine. Transport Means, 2017, p. 699-703.

[3] Loutas T. H., Sotiriades G., Kalaitzoglou I., Kostopoulos V. Condition monitoring of a single-stage gearbox with artificially induced gear cracks utilizing on-line vibration and acoustic emission measurements. Applied Acoustics, Vol. 70, 2009, p. 1148-1159.

[4] Razpotnik M., Bischof T., Boltežar M. The influence of bearing stiffness on the vibration properties of statically overdetermined gearboxes. Journal of Sound and Vibration, Vol. 351, 2015, p. 221-235.

[5] Kumar A., Jaiswal H., Jain R., Patil P. P. Free vibration and material mechanical properties influence based frequency and mode shape analysis of transmission gearbox. Procedia Engineering, Vol. 97, 2014, p. 1097-1106.

[6] Řehák K., Prokop A. Numerical simulation of single stage gearbox with tooth damage. Vibroengineering Procedia, Vol. 7, 2016, p. 88-92.

[7] Ǩehák K., Kopečková B., Prokop A. Gear Drive System Simulation with Different Model of Input Speed. Acoustics and Vibration of Mechanical Structures. Springer Proceedings in Physics, Springer, Cham, 2017, p. 331-339.

[8] Kiekbush T., Sappok D., Bernd S., Ian H. Calculation of the combined torsional stiffness of spur gears with two- and three-dimensional parametrical FE models. Journal of Mechanical Engineering, Vol. 57, 2011, p. 810-818.

[9] Prokop A., Rehák K. Virtual prototype application to heavy-duty vehicle gearbox concept. Engineering Mechanics, Vol. 1, Issue 2017, 2017, p. 810-813.

[10] Prokop A., Kučera P., Řehák K. Heavy-duty transmission gear shift investigation by virtual prototypes. Vibroengineering Procedia, Vol. 18, 2018, p. 226-230. 